Veelal wordt dit niet ingezien. Te veel ziet men naar het verschil in werkzaamheden tusschen beide groepen van accountants, doch dit is niet principieel, al is het wel van groot belang.

En juist om dit verschil te accentueeren, komt het mij noodzakelijk voor de titelaanduiding van publieke- en overheidsaccountants te doen afwijken..

't Bedrijfsleven moet weten, als een overheidsaccountant op bezoek komt, dat dit een accountant-ambtenaar is, niet een ambtenaar in 't algemeen.

't Publieke accountantsberoep moet weten dat deze collega onder geheel andere verhoudingen zijn taak moet vervullen dan hijzelf.

Alleen dan kan ieder voor zich duidelijk overzien wat hem te doen staat.

De aan 't slot van ' $t$ artikel van collega Schippers naar voren gebrachte problemen (vereeniging van accountants met gelijkgerichte bijzondere belangen, organisatie van het overheidsaccountantsberoep) zullen behandeld worden in mijn naschrift op 't artikel van collega Van Gent.

Slechts wil ik opmerken dat mijn artikel „ordening van het accountantsberoep" een ruimere strekking had dan alleen de behandeling van de „wettelijke regeling van het accountantsberoep."

Wat betreft de organisatie van het overheidsaccountantsberoep zij verwezen naar de laatste zin van mijn artikel, waaruit toch wel duidelijk blijkt dat ik geen oogenblik gedacht heb deze aan de wettelijke regeling van het accountantsberoep te verbinden. Van verwarring - welke collega Schippers blijkbaar ducht - kan dan zeker ook geen sprake zijn.

W. N. DE BLAEY.

\title{
EENIGE VERDERE AANTEEKENINGEN OVER DE AANTREKKING VAN BUITENLANDSCH KAPITAAL EN DEVIEZENPOLITIEK
}

\author{
door Drs. L. F. A. M. de Bruyn
}

\begin{abstract}
.The man who employs his capital in land has it more under his view and command and his fortune is much less liable to accidents than that of the trader, who is obliged frequently to commit it, not only to the winds and the waves, but to the more uncertain elements of human folly and injustice by giving great credit in distant countries to men with whose character and situation he can seldom be thoroughly acquainted".
\end{abstract}

Adam Smith ,"The Wealth of Nations".

Ondanks de door Adam Smith genoemde nadeelen der buitenlandsche investeeringen ten opzichte van de binnenlandsche, heeft de kapitaalexport zich ontwikkeld tot een verschijnsel, zonder hetwelk de enorme groei van het economisch leven in de vorige en in het begin dezer eeuw, niet denkbaar zou zijn geweest. Toch hebben de buitenlandsche beleggers steeds zich hunne bijzondere risico's voor oogen moeten houden, want al te vaak bleken bij de debiteuren die elementen aanwezig te zijn, welke Smith zoo typisch als ondeugdzaam karakteriseerde.

$\mathrm{Nu}$ de economische constitutie van vele landen door de juist beëindigende catastrophe weer zoodanig is verzwakt, dat opbouw en herstel de hulp van het buitenlandsche kapitaal niet kunnen ontberen, zien de kapi- 
taalverschaffers zich weer geplaatst voor de beoordeeling en de berekening hunner risico's, waarvan zij de beschikbaarstelling van hun vermogen afhankelijk zullen stellen.

Bij de door Smith bedoelde beleggingsrisico's heeft zich sinds de crisis der 30-iger jaren een nieuw element van onzekerheid gevoegd, met name het transferrisico. Hierdoor werd in vele gevallen de beschikkingsmogelijkheid over de opbrengsten uit achteraf juist gebleken beleggingen zoodanig verminderd, dat het uiteindelijke rendement toch geheel onbevredigend werd voor den buitenlandschen belegger. Wat betreft de vrijgevallen deelen van hoofdsommen werd door de transfermoeilijkheden verhinderd, dat zij elders rendabeler en veiliger geinvesteerd konden worden.

Dit transferrisico nu zal blijven bestaan tot een algemeen vrij valutaverkeer zal zijn hersteld. En hoewel de kansen ter verwezenlijking hiervan door het aanvaarden der overeenkomsten van Bretton Woods voor de toekomst groot lijken, moet de kapitaalverschaffer van vandaag het transferprobleem nog duidelijk voor oogen houden.

Het is dan ook alleszins verklaarbaar, dat dit onderwerp op dit oogenblik door den Heer Spinosa Cattela aan de orde wordt gesteld. ${ }^{1}$ )

Het betreffende artikel zal echter voor menigeen tal van onduidelijkheden bevatten en het behoeft daarom, voordat de daarin gedane suggesties kunnen worden bekeken, eerst eenige nadere aanvulling.

$\mathrm{R}$. Polak ${ }^{2}$ ) maakt ten aanzien van de investeering van vreemd kapitaal de onderscheiding tusschen actief en passief beleggingskapitaal. Bij het eerste verkrijgt de kapitaalverschaffer door middel van zijn belegging in een onderneming tevens invloed op de door die onderneming gevoerde bedrijfspolitiek, het laatste geeft alleen recht op kapitaalopbrengst, docn verleent geen macht tot medewerking in de leiding der onderneming. Deze onderscheiding is niet identiek met die in aandeelen- en obligatiekapitaal. Het is immers denkbaar, dat groepen obligatiehouders ter beveiliging hunner belangen zeggenschap in de leiding der onderneming verwerven, terwijl van de andere kant het aandeelenkapitaal geenszins steeds actief is.

Polak wijst er op, dat sommige landen meer voorkeur vertoonen voor de passieve, andere voor de actieve beleggingen. Tot het eerste type behoorde vanouds Frankrijk, tot de laatste categorie moeten ongetwijfeld de Vereenigde Staten worden gerekend. Op handelspolitieke gronden mag men ook verwachten, dat de toekomstige Amerikaansche investeeringen in het buitenland een actief karakter zullen hebben, daar van dergelijke beleggingen ongetwijfeld een stimulans verwacht wordt voor den door de Amerikanen zoo zeer begeerden export.

Wanneer de Heer Cattela de aantrekking van Amerikaansch kapitaal als noodzakelijk voorziet, dan is het dus alleszins begrijpelijk, dat hij zonder nadere aanduiding zijn onderzoek beperkt tot de actieve investeeringen. Dit diende echter duidelijkheidshalve nadrukkelijk vermeld te worden, daar de problemen der passieve beleggers hierdoor buiten het onderzoek vallen.

De actieve investeeringen zullen zich voornamelijk voltrekken in één der volgende vormen:

I. met het buitenlandsch kapitaal vindt een infiltratie plaats van buitenlandsche invloeden in de leiding van bestaande ondernemingen;

II. het buitenlandsch kapitaal kan in het betreffende land nieuwe ondernemingen stichten;

III. het buitenlandsch kapitaal kan worden geinvesteerd bij den weder-

1) Maandblad voor Accountancy en Bedrijfshuishoudkunde Maart 1946.

2) Raphael Polak, Wering van vreemden invloed uit nationale ondernemingen, Proefschrift Amsterdam 1918, pag. 34. 
opbouw of de uitbreiding van bestaande gelieerde ondernemingen.

De beide laatste figuren zullen het meest voorkomen, daar de bestaande nationale ondernemingen angstvalig zullen trachten buitenlandsche invloeden wit har leiding te weren.

De meest geëigende financiers van de nieuwe of uit te breiden ondernemingen zullen de internationale concerns blijken te zijn. Reeds in 1930 waren volgens Treep ${ }^{3}$ ) , de $z g$. direct investments d.w.z. de participaties van Amerikaansche handels- en industrieele vennootschappen in het buiterland even groot als de buitenlandsche beleggingen van particulieren". De verwachting mag dus worden uitgesproken, dat ook nu een belangrijk deel van de Amerikaansche kapitaalexport zal geschieden in concernverband. De Heer Cattela neemt dit zonder meer aan, wat moge blijken uit de volgende punten.

Welke kapitaalverschaffer, zal, behalve wanneer het de firanciering van een dochteronderneming door de moedermaatschappij betreft, de eisch kunnen stellen, dat de vrijgevallen afschrijvingsquoten van vaste activa aan hem moeten worden terugbetaald? Voor de zelfstandige ondernemingen zou dit beteekenen, òf geleidelijke liquidatie van een deel van het actief, wat voor een industrieele onderneming in strijd is met het beginsel der continuiteit, of het beteekent, dat wanneer het betrokken. actief opnieuw moet worden aangeschaft, een hernieuwd beroep op de kapitaalmarkt zal moeten worden gedaan. Ook de hiermede gepaard gaande onzekerheden kunnen het voortbestaan der onderneming bedreigen. Voor de zelfstandige onderneming is dus de figur van terugbetaling der afschrijvingsquoten niet wenschelijk. $Z_{i j}$ kan natururlijk deze bedragen tijdelijk ter beschikking stellen aan een binnenlandsche bank, die dan deze middelen tijdelijk kan doorgeven aan een ander binnenlandsch bedrijf, dat juist op dat oogenblik er behoefte an heeft. Hier blijft echter de financieringsband tusschen den buitenlandschen crediteur en de

binnenlandsche onderneming gecontinueerd. Geheel anders is de verhouding binnen het concern. Hier kan en zal in vele gevallen de nivelleering der kapitaalbehoeften binnen het concernverband plaats vinden. Een verschijnsel, dat Treep nader aanduidt. 4) Hiertoe zal gebruik gemaakt moeten worden van de geëigende juridische constructies. De moedermatschappij kan hier bijv. door de financiering te doen geschieden in de vorm van een obligatieleening het aflossingplan hiervan paraliel laten loopen met de te verwachten vrijkomende afschrijvingsquoten en deze gelden op deze wijze naar zich toe trekken. Hier kan wel tot een tijdelijke gedeeltelijke liquidatie der dochteronderneming worden overgegaan, omdat de band met de financieringsbron verzekerd blift. De uitgelote obligaties kunnen in dit geval dan tevens de titel voor den transfer vormen.

Vervolgens bepleit de Heer Cattela een juiste kapitalisatie i.e. een juiste verhouding van het eigen tot het vreemd kapitaal bij de credietopnemende onderneming. Ook deze opmerking kan nauwelijks niet-concernverhoudingen betreffen, daar iedere zelfstandige onderneming minstens een bankabele balans zal moeten toonen, voordat er sprake kan zijn van de aantrekkingen van vreemde middelen. Bij de financiering van dochtermaatschappijen in concernverband bestaat echter wel de tendens om het eigen kapitaal krap te houden, een verschijnsel, waar ook Treep ${ }^{5}$ ) op wijst.

Tenslotte gaat de Heer Cattela ervan uit, dat gelijktijdig met de kapitaalverschaffing ook immaterieele goederen en diensten aan de kapitaal-

3) Dr. A, Treep, Het Internationale concern als Kapitalexporteur, utt Economische Opstellen aangeboden aan Prof. Mr. F. de Vries, Haarlem 1944, pag. 421.

4) Treep t.a.p. pag. 435 .

5) Treep, t.a.p. pag. 436 . 
opnemende onderneming worden verstrekt in den vorm van licencies, technische hulp etc. Buiten de concernverhouding zal ook deze figuur weinig voorkomen.

De schrijver behandelt dus slechts dat deel der actieve buitenlandsche kapitaalverstrekking, dat geschiedt in concernverband. Het is zonder meer duidelijk, dat het verwarrend moet werken, een studie met een beperkt object zonder nadere aanduiding een te breede strekking toe te meten.

$\mathrm{Na}$ aldus het terrein van het onderzoek te hebben afgebakend kunnen de suggesties van den Heer Cattela aan een nadere beschouwing worden onderworpen.

Het kardinale punt uit zijn betoog is, dat de medewerking der buitenlandsche kapitaalbezitters te verkrijgen is op voorwaarde, dat de zekerheid bestaat de kapitaalopbrengsten en vrijgevallen kapitaalbestanddeelen te kunnen transfereeren.

Allereerst dient hiertoe de toekomstige deviezenpositie van het kapitaalaantrekkende land voldoende te worden geacht (niet door het weer aantrekken van buitenlandsche credieten, denk aan de catastrophe der Duitsche herstelbetalingen!), en eenmaal aan deze voorwaarden voldaan wordt er een aantal regelen voor het beheer der kapitaalopnemende ondernemingen gegeven, die, doordat zij een onjuiste kapitaalafzuiging, uit de onderneming zouden verhinderen, tegelijkertijd het debiteurenland zullen beschermen tegen overmatig deviezenverlies. Met andere woorden wordt een juist beheer dezer ondernemingen gevoerd, dan zijn de vrijvallende kapitaalopbrengsten en afschrijvingsquoten automatisch door de deviezen autoriteiten als transferabel te beschouwen.

Ten aanzien van de winst zal dit inderdaad het geval zijn. Wordt nu echter met de suggesties dienaangaande een nieuw perspectief -geopend?

Ter verzekering van de continuiteit der onderneming zal ook in concernverhoudingen ervoor gewaakt worden, dat door onjuiste afschrijvingsen reservepolitiek de winstvaststelling gaat ten koste van het vermogen der dochteronderneming. Daar dus in het algemeen de neiging zal bestaan de winst conservatief te berekenen, kunnen er nauwelijks bezwaren van de zijde der deviezenautoriteiten verwacht worden wanneer men tot transfer zou willen overgaan. Speciaal niet, wanneer de winst toevalt aan een voldoende groot eigen kapitaal, zoodat het dividendpercentage geen excessieve vormen zal aannemen. Ook in dit opzicht is dus een juiste kapitalisatie wenschelijk. De transfertitel wordt hier dan ontleend aan de dividenduitkeering, welke een alleszins redelijke vergoeding vormt voor de beschikbaarstelling van het kapitaal verhoogd met een risicopremie.

Vervolgens wordt besproken de overmaking van vrijgevallen kapitaalbestanddeelen. Bij de financiering van zelfstandige ondernemingen zal, zooals reeds werd aangetoond, dit verschijnsel zich niet voordoen. Wordt er in een corcern wel toe overgegaan, dan vindt hier geen transfer plaats in dezelfde zin als bij winsttransfer, daar hier geen deviezenafvloeiing plaats vindt, welke een eenzijdige belasting van de betalingsbalans beteekent. De moedermaatschappij zal immers normaliter het voortbestaan der dochteronderneming willen verzekeren en zal t.z.t. een nieuw kapitaal. goed aan haar doen terugkeeren. Men zou hier hoogstens kunnen spreken van een schijntransfer.

Gaat men den weg der geleidelijke afschrijvingen dan zal zooals reeds aangetoond de financiering dienen te geschieden in den vorm van een obligatieleening. $\mathrm{B}_{\mathrm{ij}}$ het overmaken van de opbrengst der uitgelote obligaties zal hier tijdelijk een eenzijdige belasting plaats vinden van de betalingsbalans, waartegenover de zekere levering staat op een later tijdstip van het nieuwe kapitaalgoed. Deze levering zal dan moeten plaats vinden in het kader van een nieuwe credietovereenkomst al dan niet in den vorm van een obligatieleening. 
Vindt daarentegen een accumulatie der afschrijvingsquoten plaats bij de dochteronderneming, dan wordt zelfs de schijn van transfer vermeden en vindt er slechts betaling plaats aan het buitenland voor de aanschaffing van een nieuw kapitaalgoed.

In beide gevallen wordt de deviezenpositie van het debiteurenland niet door een eenzijdige afvloeiing bedreigd, zoodat de deviezenautoriteiten tegen de genoemde procedures nauwelijks bezwaar zullen inbrengen.

Het zou natuurlijk de onderhandelingen met de deviezenautoriteiten zeer vergemakkelijken, wanneer het deel der afschrijvingen, dat vrijkomt uit exporten, als zoodanig kon worden gelocaliseerd. (Mutatis mutandis geldt dit natuurlijk ook voor de transfer van winsten). In de practijk zal echter van dit z.g. „equity character" der investeeringen in concernverband weinig terecht komen, daar de dochterondernemingen een belangrijk deel hunner productie in het binnenland zullen afzetten.

Voor dit laatste geval neemt de Heer Cattela aan, dat bij een sluitende betalingsbalans toch deviezen voor de vernieuwing resp. voor de overmaking der afschrijving ter beschikking zullen worden gesteld. Verwacht hij echter nog deviezencontrôle bij een sluitende betalingsbalans?

Het gevaar, dat bij het geleidelijk overmaken der afschrijvingsquoten ook de tegenwaarde van de met binnenlandsche betaalmiddelen gedane uitgaven voor kapitaalgoederen zal worden getransfereerd, is reëel, en de door den Heer Cattela voorgestelde splitsing der kapitaalgoederenrekening zal zeker fouten in dit opzicht kunnen voorkomen. Ook de deviezenautoriteiten zullen bij hun beoordeeling der betreffende transferaanvrage zeer zeker gunstig worden gestemd.

Tenslotte behandelt de schrijver de overmaking van de vergoedingen voor gepresteerde diensten zooals licenties, technische hulp, etc.

De transfertitel, in verband met de levering van dergelijke diensten, dient duidelijk onderscheiden te worden van die, krachtens welke beschikbaargekomen kapitaalopbrengsten worden overgemaakt. In principe ontstaat er bij de levering dezer diensten een schuld, evenals bij de levering van materieele goederen, die niet afhankelijk is van de rentabiliteit van de onderneming. Het feit, dat deze schuld in een percentage van den omzet wordt uitgedrukt en eerst na het effectueeren van den omzet wordt geboekt, verandert in wezen niets hieraan. In de practijk zien wij dan ook, dat de debiteurenlanden op grond van de reëele waarde van dezen bijstand deviezen ter beschikking stellen om deze immaterieele goederen te ,koopen". Zou de transfer worden geweigerd, dan blijft deze schuld in de boeken van den debiteur bestaan, tenzij deze bevrijd zou worden door storting op geblokkeerde rekening.

Het standpunt van den schrijver, dat bij een dergelijke transferweigering de berekende winst der dochteronderneming met eenzelfde bedrag zou stijgen, lijkt ons dan ook absoluut onjuist. Het is immers ook voor deviezenautoriteiten ongebruikelijk de winst te vermeerderen met nietbetaalde schulden.

Samenvattend komt het ons voor, dat de suggesties van den Heer Cattela weinig nieuwe gezichtspunten hebben gebracht. Bij een voldoende deviezenpositie, waarvan hij uitgaat, zal het niet moeilijk zijn de transfers op reëele basis te bewerkstelligen. Deze basis wordt verschaft door elk verantwoordelijk bedrijfsbeheer, dat zeker de regels in acht zal nemen, die hier worden voorgeschreven. Daar het in het opstel van den Heer Cattela concernverhoudingen betreft, zal de kapitaalverschaffer op dit beheer steeds een deugdelijke contrôle hebben, die echter zal bestaan onafhankelijk van het al of niet aanwezig zijn van transfermoeilijkheden. Het is dus onjuist om op deze wijze de beperking der transferrisico's van het concern te benaderen vanuit. de privaateconomische sfeer. Deze risico's 
bestaan echter wel, doch zijn rechtevenredig aan de externe economische positie van het debiteurenland, i.e. van deszelfs deviezenpositie.

Hoewel vallende buiten het kader van dit betoog, kan worden vastgesteld, dat ook de beperking van de transferrisico's der passieve kapitaalverschaffers nauwelijks gezocht zal moeten worden langs de door den schrijver aangegeven wegen. De passieve belegger staat vrijwel steeds machteloos tegenover het beleid der onderneming, deviezencontrôle of niet. Ook hier zal dus het transferrisico voornamelijk worden bepaald door den algemeenen economischen toestand van het debiteurenland in de toekomst.

De beoordeeling hiervan zal worden vergemakkelijkt door de houding der officieele instanties van het crediteurenland ten opzichte van te verstrekken credieten in verband met de wederopbouw van het debiteurenland. Worden officieele credieten verstrekt, dan zullen deze de wederopbouw stimuleeren, waarvan ook de toekomstige betalingsbalanspositie den gunstigen invloed zal ondergaan. Tevens kan uit deze credietverleening zelf het vertrouwen blijken, dat de officieele instanties koesteren ten opzichte van de toekomst van het debiteurenland, zoodat het waarschijnlijk mag worden geacht, dat de overheidscredieten tevens de aantrekking van het particuliere kapitaal zullen bevorderen.

\section{Naschrift.}

De redactie was zo vriendelijk mij voor de plaatsing kennis te doen nemen van de inhoud van het bovenstaande artikel van Drs. L. F. A. M. de Bruyn, waarin teruggekomen wordt op de vraagstukken, door mij aangeroerd onder de titel ",Aantrekking van Buitenlands Kapitaal en Deviezenpolitiek."

Enkele opmerkingen in de "Aanteekeningen" van den Heer De Bruyn geven mij aanleiding op enige punten nader in te gaan. De schrijver meent n.l. uit mijn woorden op te moeten maken dat ik bij mijn betoog voornamelijk, zo niet uitsluitend, het oog had op investeringen door buitenlandse concerns in de vorm van z.g. actieve kapitaalsinvesteringen. In feite echter had ik een andere situatie op het oog, waarbij ik moet toegeven, dit - behoudens de dagtekening - niet uitdrukkelijk vermeld te hebben. Met name had ik het oog gevestigd op de vraagstukken, die zich voordoen in een land met een overwegend "koloniale" economie. Het woord "koloniale" dan hier uitsluitend gebruikt ter kenmerking van de typische economische structuur, zoals die, althans tot voor de oorlog, bijv. in de Indonesische archipel bestond. Daarbij was vrijwel het gehele kapitaal van het Westers geleide bedrijfsleven (incl. het bankwezen) van het buitenland - deviezen-technisch hieronder ook Nederland te verstaan afkomstig. In vele dier gevallen was de directie der onderneming in het buitenland gevestigd en werden de besluiten omtrent de financieele politiek aldaar genomen. Dit had in vele gevallen een dusdanige invloed op de betalingsbalans, dat men zich soms gerechtigd voelde van "drainage" of ,economic drain" te spreken. Zonder nu op de juistheid of de onjuistheid van dit woord in dit verband nader in te gaan, kan toch vastgesteld worden, dat de economische structuur van een gebied als de Indonesische archipel een geheel andere is dan die van Nederland, en zich mitsdien op het gebied van deviezenpolitiek en betalingsbalans andere vraagstukken voordoen.

In zekere zin redeneren dus de heer De Bruyn en ik langs elkaar. De heer De Bruyn houdt zijn gedachten uitsluitend gevestigd op de toestanden, zoals die zich o.a. in Nederland voordoen, ik daarentegen had het 
oog op landen met de z.g. koloniale economische structuur. De schuld hiervan ligt bij mij; een beter opschrift had dit misverstand bij voorbaat kunnen voorkomen.

In dit licht bezien, zal de vraag van den heer De Bruyn: „Welke kapitaalverschaffer zal de eis kunnen stellen, dat de vrijgevallen afschrijvings quoten van vaste activa aan hem moeten worden terugbetaald"? niet beantwoord behoeven te worden met: „Dit kan uitsluitend het geval zijn, indien er een concernverhouding aanwezig is", daar immers, zoals de praktijk heeft aangetoond, deze eis gesteld wordt door vrijwel alle kapitaaleigenaren in het buitenland, die de liquiditeit hunner overzeese bedrijven door die vrijgevallen afschrijvingen zagen toenemen. Aangetekend moet hierbij worden, dat het ontbreken van voldoende mogelijkheid tot belegging van die vrijgevallen gelden in het overzeese gebied, deze eis verklaart.

$\mathrm{Nu}$ betoogt de Heer De Bruyn echter, dat de overmaking van de afschrijvingsquote naar de moedermaatschappij (ik volg hierbij zijn gedachtengang van concern-verhouding) slechts hoogstens een schijn-transfer is, omdat de moeder-maatschappij ,.immers normaliter het voortbestaan der dochtermaatschappij (zal) willen verzekeren en t.z.t. een nieuw kapitaalgoed aan haar (zal) doen terugkeren". Afgescheiden van het feit, dat ik de term ",schijn-transfer" in dit verband niet geheel juist acht, indien daarvoor in feite een deel van de voorraad buitenlandse betaalmiddelen (het deviezen-vermogen) wordt aangesproken, moet opgemerkt worden, dat ook in mijn artikel betoogd werd, dat de overmaking van de afschrijvingsquoten diende vrijgegeven te worden, doch dat daarentegen voor de aanschaffing van nieuwe activa, inclusief die voor de reconstructie benodigd, geen deviezen kunnen worden vrijgegeven, daar immers èn in het verleden èn in de toekomst de afschrijvingen werden, resp. zullen worden overgemaakt. Een uitzondering makte ik slechts voor de gevallen, waarin, naar het oordeel der bevoegde instanties, de oprichting van nieuwe bedrijven (of uitbreiding van bestaande) moet geacht worden een landsbelang te zijn.

En thans nog een enkel woord omtrent de beloning van diensten e.d. De heer De Bruyn merkt op, dat indien deze overmaking niet wordt toegestaan, het bedrijf deze beloningen toch zal boeken en ze mitsdien als niet-overmaakbare schulden in de boeken zullen voorkomen. Dit moge in de theorie juist lijken, de praktijk leert echter anders.

De diensten worden gepresteerd of door de kapitaaleigenaars, of door derden, niet-kapitaaleigenaars. Worden de diensten gepresteerd door den kapitaal-eigenaar zelf, dan zal hij, wetende dat een overmaking van dergelijke beloningen niet mogelijk is, ervan afzien een daarop betrekking hebbende overeenkomst af te sluiten, en zal dus de winst met een dienovereenkomstig bedrag toenemen. Immers, niemand kan hem beletten zijn diensten gratis aan het bedrijf ter beschikking te stellen, in het vooruitzicht van hoogere winsten. Worden de diensten niet door den kapitaaleigenaar gepresteerd, doch door derden, dan zal niettemin de kapitaaleigenaar de aansprakelijkheid voor de beloning daarvan moeten aanvaarden. In dat geval zal dus de derde die de diensten presteert, eveneens wetende, dat overmaking zijner beloning niet mogelijk zal zijn, er de voor keur aan geven een overeenkomst af te sluiten met den (buitenlandsen) kapitaaleigenaar, die hem dan een deel der getransfereerde winsten als beloning zou moeten afstaan, of hij zal er de voorkeur aan geven een overeenkomst af te sluiten, waarbij hij zijn toekomstige beloningen in de een of andere vorm kapitaliseert, om aldus in de winstuitkering op de verkregen aandelen zijn beloning te vinden. Hierbij komt het vraagstuk van de winstuitkeringen in de gevallen, waarin immateriële activa zijn ingebracht, 
ter sprake. In het kader van dit naschrift behoeft hier echter niet dieper op in gegaan te worden.

Hoe het ook zij, de stelling van den heer De Bruyn, dat de niet overmaakbare beloningen van diensten als ev. geblokkeerde schulden in de boeken zullen verschijnen, zal in de praktijk blijken onhoudbaar te zijn. Als bij een onderneming de in het buitenland gevestigde directie (de technische leiding, de inkoopafdeling, het laboratorium) de keuze heeft tussen het doen boeken van haar beloningen met het risico van de nietovermaakbaarheid, en het niet doen boeken van dergelijke beloningen, dan zal deze keuze haar niet moeilijk vallen. Vandaar dan ook, dat ik betoogde, dat het uit een deviezenoogpunt onverschillig kan zijn of men met winstovermakingen "tout purs" of met gedeeltelijke overmaking van beloningen voor gepresteerde diensten te doen heeft.

Ten slotte nog de door den heer De Bruyn tot mij gestelde vraag, of ik nog deviezencontrole bij een sluitende betalingsbalans verwacht. In de eerste plaats diene hier ten antwoord, dat ik de deviezencontrole niet zie als een geheel op zichzelf staande maatregel, doch als een onderdeel van het gehele systeem der geleide of gebonden economie. Of we nu daarin de oplossing zien voor de noden dezer tijden, of dat we menen daarin tegen onze wil in verzeild geraakt te zijn, doet niets ter zake. De geleide economie ,est en marche et rien ne l'arrêtera". Overigens dient onderscheid gemaakt te worden tussen een, bij een bestaande deviezencontrole, "sluitende" betalingsbalans en een betalingsbalans, welke ook zonder deviezenbepalingen een voordelig saldo zou opleveren, resp. juist zou .sluiten".

De redactie heeft gelijk gehad toen zij wees op de vele facetten van dit onderwerp. „Du choc des opinions jaillit la vérité".

Melbourne, 21 Juli 1946.

J. E. SPINOSA CATTELA.

\section{DE FINANCIERING VAN DE VERPLICHTE ZIEKENFONDSVER- ZEKERING INGEVOLGE HET ZIEKENFONDSENBESLUIT.}

door Th. M. van Erp.

Op 1 Augustus 1941 verscheen in het Verordeningenblad een besluit van den waarnemend Secretaris-Generaal van het Departement van Sociale Zaken, dat bekend is geworden onder de naam Ziekenfondsenbesluit.

Aan dit besluit lagen voor een niet-onbelangrijk deel politieke bedoelingen ten grondslag en dit heeft tengevolge gehad, dat de invoering zeer overhaast is geschied. De onvoldoende voorbereiding - waarvoor overigens den Nederlandsen ambtenaren geen verwijt kan worden gemaakt heeft zich natuurlijk gewroken en de bij de uitvoering aan het licht tredende leemten en fouten moesten zo goed en zo kwaad als dat ging worden aangevuld en gecorrigeerd door wijzigingen in het Besluit, door Uitvoeringsbesluiten en door circulaires van den krachtens het Ziekenfondsenbesluit benoemden Commissaris, belast met het toezicht op de Ziekenfondsen.

De verplichte verzekering geldt voor personen, die naar de voorschriften der Ziektewet verzekeringsplichtig zijn, benevens voor de leden van hun gezin, wier kostwinner zij zijn. Het besluit noemt hen resp. rechtstreeks-verzekerden en indirect-verzekerden. Voorwerp der verzekering 